\title{
Productivity Improvement of a Special Purpose Machine Using DMAIC Principles: A Case Study
}

\author{
Sunil Dambhare, ${ }^{1}$ Siddhant Aphale, ${ }^{2}$ Kiran Kakade, ${ }^{2}$ Tejas Thote, ${ }^{2}$ and Atul Borade ${ }^{3}$ \\ ${ }^{1}$ Department of Mechanical Engineering, PVPIT, Bavdhan, Pune, Maharashtra 411021, India \\ ${ }^{2}$ Mechanical Engineering, PVPIT, Bavdhan, Pune, Maharashtra 411021, India \\ ${ }^{3}$ Department of Mechanical Engineering, JDIET, Yavatmal, Maharashtra 445001, India
}

Correspondence should be addressed to Atul Borade; atulborade@rediffmail.com

Received 5 April 2013; Revised 16 July 2013; Accepted 22 July 2013

Academic Editor: Shey-Huei Sheu

Copyright (C) 2013 Sunil Dambhare et al. This is an open access article distributed under the Creative Commons Attribution License, which permits unrestricted use, distribution, and reproduction in any medium, provided the original work is properly cited.

\begin{abstract}
Six Sigma is one of the popular methodologies used by the companies to improve the quality and productivity. It uses a detailed analysis of the process to determine the causes of the problem and proposes a successful improvement. Various approaches are adopted while following Six Sigma methodologies and one of them is DMAIC. The successful implementation of DMAIC and FTA is discussed in this paper. In this study, the major problem was of continuous rework up to $16 \%$, which was leading to wastage of man hours and labor cost. Initially, fault tree analysis (FTA) was used to detect the key process input variables (KPIVs) affecting the output. Multivariable regression analysis was performed to know the possible relationship between the KPIVs and the output. The DMAIC methodology was successfully implemented to reduce the rework from $16 \%$ bores per month to $2.20 \%$ bores per month. The other problem of nonuniform step bores was also reduced significantly.
\end{abstract}

\section{Introduction}

Diesel engines have very wide applications in this modern technological era. They are designed to cater for the need of construction, mining, power generation, locomotives, marine transport, compressors, and so forth market segments. These are heavy power requirement applications. For such applications, the output requirement may vary from 10 horsepower to 3500 horsepower. The engine with this huge power output is also huge. The firm in which this study was conducted was involved in manufacturing $1 \mathrm{~V}$ - and $16 \mathrm{~V}$ cylinder diesel engines. The sand casted engine block went through various operations and then was assembled. Operations like undercutting, water clearance chamfer, boring, step-boring, and so forth were performed on each cylinder. The step-boring operation was the most difficult operation. It needs special attention as the liner is resting in it. A cylinder liner is pressed into an engine block and houses the piston. The cylinder liner is much harder than the engine block and prevents the piston from wearing out through the cylinder bore. Typically used in aluminium engine blocks and diesel engines, the cylinder liner is either pressed into position or held in place by the cylinder head. In large engines such as the engines found in diesel locomotives, the cylinder liner is part of an assembly containing a new piston, piston rings, and a connecting rod. During scheduled maintenance or repair, the liner is changed as a complete unit. In aluminium engine blocks, the block material is too soft to house a piston. The friction of a piston moving up and down inside the alloy block would make the piston wear out, resulting in a loss of compression and severe oil consumption $[1,2]$. In such cases, the steel cylinder liner is pressed into the engine block and then the engine block is machined to assure that the cylinder head mating surface is smooth and flat. With this modification, the engine is able to operate for many years without failure. The flat surface resulting from the machining of the engine block assures a proper seal of the head between the cylinder head and the engine block. An improperly sealed head gasket will result in overheating of the engine, loss of power, and the potential to ruin the block and cylinder head. It is clear that the depth of a V-cylinder engine is one of the most crucial parameters for the efficient working 
of an engine. A slight variation in depth of the step can damage the cylinder and piston as well as hamper the engine operation. A cylinder's head and liner rest on the bored depth. Thus maintaining the depth is the necessity for any engine manufacturing firm.

Six Sigma is a business management strategy, first developed by Motorola in 1986, which seeks to improve the quality of process outputs [3]. It identifies and removes the cause of defects and minimizes variability in manufacturing and business processes $[4,5]$. A set of quality management methods and statistical methods is used. Each Six Sigma project carried out within an organization follows a defined sequence of steps and quantified financial targets. According to the definition, a Six Sigma process is one in which $99.99966 \%$ of the products manufactured are statistically expected to be free of defects (3.4 defects per million) [6-8]. Six Sigma uses a group of improvement specialists for problem solving and improving the process continuously $[9,10]$. Six Sigma techniques have two main methodologies DMAIC and DMADV [11]. Define, Measure, Analyse, Improve, and Control (DMAIC) methodology was followed for reducing the rework [12, 13]. The reasons for the main problem can be detected using again two methodologies FTA and failure mode and effects analysis. FTA deals with identifying all possible causes related to a particular problem. It is a stepwise approach to identify causes and all the parameters related to every cause. It can be used in almost every application which involves cause-effect analysis. Once the problem is defined, it is to be measured so as to collect statistical data about the problem. Once the statistical data is collected, it is analysed using various analysis techniques like chi-square test, regression analysis, ANOVA, and so forth. Minitab statistical software was used for the analysis of various phases of the project.

\section{Review of the Literature}

Six Sigma methodologies have become a top agenda for many companies which are continuously trying to improve productivity at lesser costs. It was shown previously that Six Sigma continued to be a predominate target to try and obtain a competitive advantage [11]. Many Fortune 500 companies have adopted Six Sigma to improve the productivity and reduce cost. Six Sigma has been described as a data driven approach for problem solving, business process, disciplined statistical approach, and a management strategy [14-18]. Six Sigma methods can prove to be beneficial when applied to labour-intensive, repeatable processes according to Swink and Jacobs [14]. Six Sigma benefits are significantly correlated with intensity in manufacturing and with financial performance before adoption in services [14]. The Six Sigma improvement method is problem-focused and its main objectives are decreasing scrap, earning income, and creating value. Previous researches have shown the effective implementation of Six Sigma techniques in problem solving and process improvements. FTA was successfully utilised to analyse the bridge erecting tripping problem [19]. FTA can be used to analyse hazards and calculate system reliability for simple as well as complex systems [20]. Six Sigma methodologies have been previously used for reducing the rejection level [21].
FTA can be effectively used for finding the effective causes from accident cases to scrap reduction [22]. According to Wang et al. [23], FTA is a simple, effective, reliable method which is recognised internationally and is used on guiding system optimization and analysing and repairing the system of weak links. FTA helps deepen the research to find out the possible causes for the fault [24]. FTA has previously been used successfully to establish priorities for the manufacturing plant for future projects aimed at improving the manufacturing plant [25].

According to Büyüközkan and Öztürkcan [4] and de Koning and de Mast [26], Six Sigma program offers a wide range of tools and techniques, which might be statistical and nonstatistical, that are intended to assist the project leader. Swink and Jacobs [14] showed solid support for the hypothesis that Six Sigma adoption tends to produce significant benefits for firm's profitability. Positive return on asset (ROA) changes were frequently observed in latter periods (years +3 and +4 ), and moreover these benefits also appear to be persistent. These findings hint at potential differences in how Six Sigma programs are possibly being applied in front-office versus back-office contexts. Findings suggest that Six Sigma methods may be most beneficial when applied to labour-intensive, repeatable processes. However, less labourintensive, quality experienced, manufacturing firms will not experience the profit impact from Six Sigma adoption the same way that others will. Their outcomes also revealed marginally significant positive effects on sales growth Six Sigma projects can accomplish successfully using FTA. FTA has been used extensively by the military, the space program, and nuclear industry. FTA is a very structured, systematic, and rigorous that lends itself well to quantification [25]. FTA can be used to express the logical relationship between the possibility of certain accident and causes of undesired events or accidents in fault tree diagram [19]. It could be successfully implemented to find out all the possible causes for the problem or fault that has occurred. According to Shalev and Tiran [20], FTA method analysts apply top-down logic in building their models. The problem of reducing process variation and the associated defect rate can be solved using the DMAIC methodology of Six Sigma. Six Sigma is a useful problemsolving methodology and provides a valuable measurement approach. Six Sigma focuses on some vital dimension of business processes, reducing the variation around the mean value of the process [20]. The original task of Six Sigma's DMAIC Methodology is variation reduction. As stated by de Mast and Lokkerbol [27], Six Sigma and its DMAIC are built on insights from the quality engineering field, incorporating ideas from statistical quality control, total quality management, and Taguchi's offline quality control. It has also been used for general tasks like quality improvement, efficiency improvement, cost reduction, and other pursuits in operations. Thus Six Sigma is a generic method and its original task domain was variation reduction, typically in manufacturing processes. Li et al. [28] successfully implemented DMAIC approach to improve the capability of the solder paste printing process by reducing thickness variations from a nominal value. The DMAIC approach has shown a wider application and how the engineering organisation can achieve competitive 

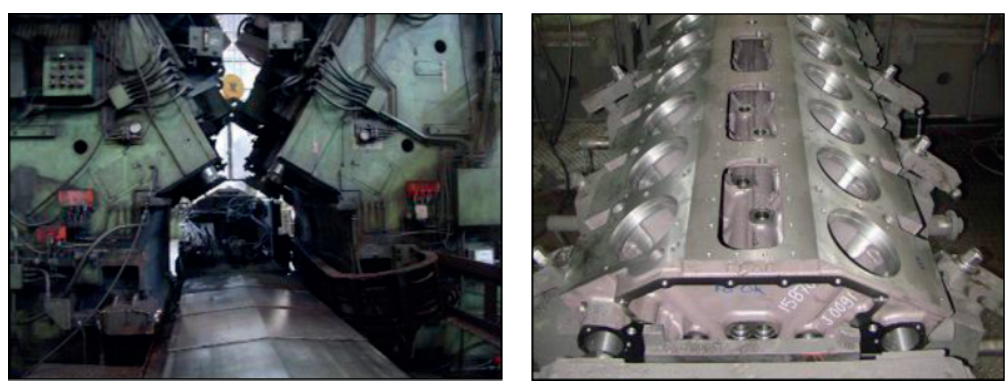

FIGURE 1: Ingersoll special purpose machine and engine block.

advantages, efficient decision making, and problem-solving capabilities within a business context. According to Li and AlRefaie [29], adopting the DMAIC procedure including GR\&R study turns out to be an effective method in improving the quality system including measurements.

\section{Background for the Study}

The case study was conducted at a leading manufacturer of $12 \mathrm{~V}$ - and $16 \mathrm{~V}$-cylinder diesel engines. The sand casted engine block is processed with operations like rough boring, water clearance chamfer, surface milling, finish boring, and so forth before accomplishing the engine assembly. Critical operations which demand precise dimension control are performed on special purpose machines. Engine block boring is one of the critical operations performed on special purpose machines under study.

The finished boring operation is completed in 3 stages. Initially, the $\mathrm{V}$-surface of the engine is milled using milling head. Considering the milled surface as datum, step-boring operation and water clearance chamfering operation are performed. As the engine is a $\mathrm{V}$-cylinder engine, performing machining operations on the block is a tedious task. If these operations are performed on a $\mathrm{CNC}$ machine, it requires nearly 5 hours and tiresome programming. Thus there was a need of special purpose machine.

Ingersoll machine performs the mentioned operations in 17 minutes approximately. The machine uses hydraulic circuits for performing operations which were designed around 40 years back. The machine performs three operations on each bore, namely, undercutting, chamfering, and step-boring, after performing milling on the V-surface. Operations are carried out in a sequence as undercut/chamfering/ step-boring. Machine starts its forward stroke at 800 psi pressure acting in forward direction. In this stroke it performs two operations, undercutting and chamfering. Both operations are carried out at $800 \mathrm{psi}$ pressure and flow control valves are used to control speed of sliding tool during operations. After completion of chamfering, tool slide completes the forward stoke and at the same time a lever attached to the tool post touches the inclined milling surface, actuating the boring tool slide mechanism. This provides forward motion to the boring tool. Simultaneously, the lever actuates return pressure valve and 1000 psi pressure acts to carry out backward stroke of the tool post slide. Step-boring finishing operation is completed in return stroke of tool post. Once tool post returns to its original position, another engine bore gets lined for the same set of operations. Figure 1 shows the Ingersoll special purpose machine and the engine block machined using this machine.

\section{Case Study}

The machine under consideration is a special purpose machine which was specially developed for performing the specified operations on the V-engines manufactured by the firm. The operations performed are milling, of the V-surface where the material on the surface is removed. After milling, crevice chamfering is completed. Step-boring is performed at last in which the existing hole is enlarged to the designed depth. The step bore is a critical dimension as the liner of the cylinder rests on it. The boring tool performs the operation, and after it reaches the required depth, a lever senses its position. As soon as the lever touches the surface, the boring tool retracts and the operation is completed.

During the study, readings for the step bore depth were noted for every bore of each engine block. The allowable tolerance for the step bore was $0.7190^{\prime \prime} \pm 0.0013^{\prime \prime}$. From the data, it was observed that there was a variation in the readings and many of the readings were outside the tolerance limit of $0.7190^{\prime \prime} \pm 0.0013^{\prime \prime}$. This was a serious problem. Bringing the dimension within the tolerance limits means rework on the bores was necessary. The rework data was gathered and it was found that average rework per month was $16 \%$ of the bores machined. For performing rework operations, 369 man-hours per month and approximately INR 60400 were spent. This hampered the productivity of the firm. The study showed that rework was needed mostly on the left bank of the engine block indicating need of the improvement actions on this section of engine boring operation. Therefore the objective of the study was set to minimize the rework percentage per month close to zero without affecting the operations and cycle time. To improve the productivity and reduce the rework expenses, the Six Sigma technique was selected.

\section{Methodology}

As the study aimed at improving the existing business process, DMAIC methodology was considered $[11,12,21,30]$. 


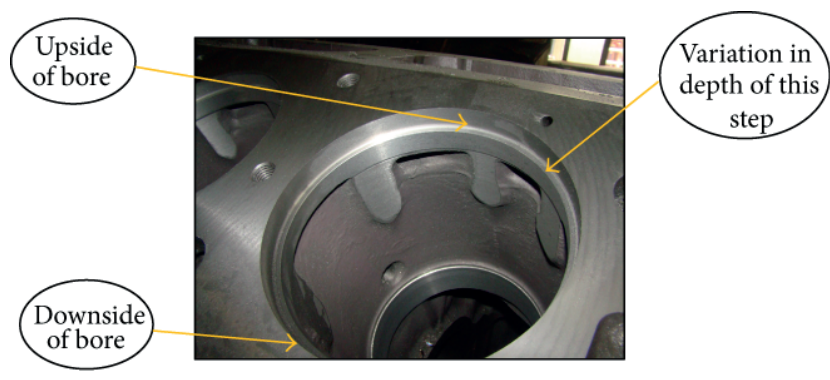

Figure 2: Step bore and depth variation.

It consists of phases, namely, Define, Measure, Analyse, Improve, and Control [31, 32]. The whole Six Sigma project starts with Define phase and is defined based on the customer requirement and company strategy and mission [33, 34]. Measure phase helps the project team to refine the problem and begin the search for various causes of the failure. In Analyse phase, the causes found are analysed using various data analysis tools and the data is validated for Improvement phase. Improvement phase helps in finding solutions and implementing them so that the problems can be eliminated. In Control phase, the performance of the process after Improvement is measured routinely and accordingly adjustments are made in operations. If the Control phase is not implemented, it may revert the project to its previous state.

In the case study presented, the DMAIC methodology was applied to identify the probable sources of deviation in machined surface and successfully reduced the rework to $2.20 \%$ from an initial $16 \%$ per month. The following sections explain the methodology applied for the purpose.

\subsection{Step I-Define}

Problem Statement. Reduce engine block liner bore counter depth rework close to zero from $16 \%$ bores per month without adversely affecting the cycle time.

The special purpose machine was in regular use with heavy production for a long time. Due to the continuous course of action and heavy load, parts of the machine are worn out. Thus a variation in the depth of step bore was observed as shown in Figure 1. This variation occurred on a number of blocks leading to increased rework. The major concern was the unpredictable behaviour of the machine. Each V-block has two sides: left bank and right bank when looked to from the rear end of the engine. The data showed that the majority of the rework was required on the left bank of the block. If there is a variation in the depth of the bore either if it can be reworked or if the depth is out of rework range, then the entire block is scrapped. Reworking of the cylinder bore is possible at the expense of 369 man-hours per month and approximately INR 60400.

The rework demands skilled manpower due to precise tolerances, man-/machine-hours, and other considerable resources. Thus to increase productivity and reduce the rework cost, there was a need to reduce this rework. It is expected that the depth of each bore must lie within $0.7177^{\prime \prime}$ to $0.7203^{\prime \prime}$. Based on the lower limit and upper limit of the bore, they are categorised as undersize, in size, or oversize bores. Each bore failing to achieve these tolerances was subjected to rework. The depth of the bore was measured using a depth gauge which was calibrated before data was collected. The depth gauge indicated the measured depth about the mean depth, that is, $0.7190^{\prime \prime}$. The depth was measured at two points of the bore, upside and downside of the bore on both banks, as shown in Figure 2 .

The machine behaviour was unpredictable because of the following reasons.

(1) Dimensional variation was observed mostly on the left bank of the block even under the same machining conditions on both sides.

(2) A fix pattern in dimensional variation was not observed in the finished bores. Some blocks were oversize while some were undersize. Some cases were reported where all the bore categories were involved.

(3) There was no pattern repetition in dimensional variation of the bores. If on a particular block all the bores went out of tolerance, then for the immediate next block it could be a block without any fault.

The following objectives were set to achieve the target:

(1) to reduce rework of bores from $16 \%$ bores per month close to zero without adversely affecting the cycle time,

(2) to improve the overall quality of the process,

(3) to reduce the energy consumption involved in the process by reducing the rework,

(4) to reduce the cost of rework.

5.2. Step II-Measure. In the proposed study, a variation in the depth of step bore was observed on the blocks used for V 12- and V16-engines. These variations were not uniform and of same pattern.

The detailed data for total number of bores produced from the month of April 2012 to December 2012 was collected. The up and down measurements of both banks were recorded for six months. The measurements for the engine bore which were not in the specified tolerances were also counted in all. The total number of bores produced per month was counted and accordingly the rework percentage was found out by plotting the I-MR chart as shown in Figure 3. The bores which required rework were classified into two major categories: oversize bores and undersize bores. These two categories were again divided into two subcategories depending on the banks of the block where variation was recorded, that is, left bank and right bank. For the collected data, individual value and moving range chart (I-MR) was plotted using Minitab 16 software. I-MR chart plots individual observations on one chart accompanied with another chart of the range of the individual observations, normally from each consecutive data point. Figure 3 is the I-MR chart of the rework data collected during April-December 2012. 

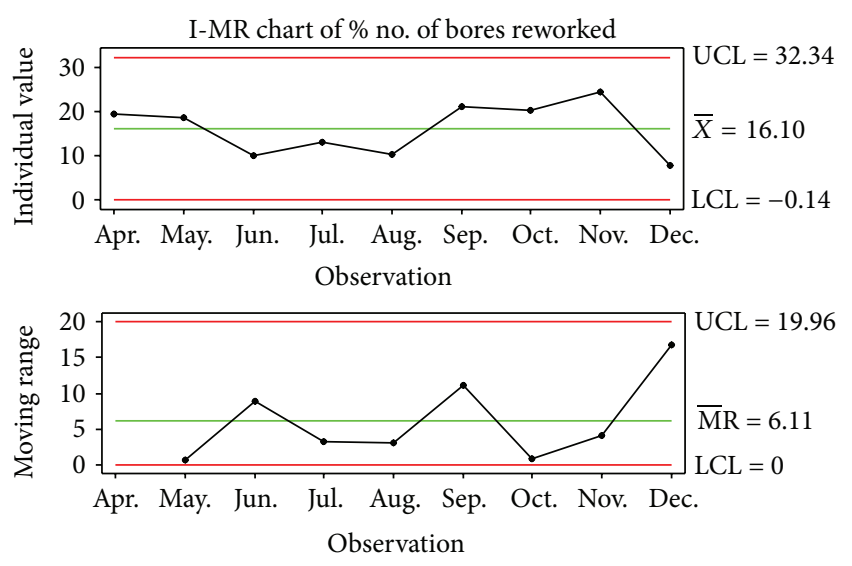

FIGURE 3: I-MR chart of rework data.

It can be inferred from Figure 3 that the average monthly block liner bores reworked for DC are $16 \%$ of total production. Each undersize bore required 10 minutes of rework time and each oversize bore required 60 minutes of rework time. The manual rework cost incurred per bore whether oversize or undersize was INR 2.33. Accordingly, eliminating rework would save monthly 369 man-hours and INR 60400 . It also saved average sleeve rework cost of INR 30000 per month. Hence the total average monthly cost saving could be INR 90400. The projected annual cost saving could be INR $1,084,800$ or USD 19,3700 approximately.

5.3. Step III-Analyse. The Analyse phase is the third and usually the longest phase in the Six Sigma methodology. Most of the crucial data analysis is performed in this phase. This eventually leads you to isolate the root causes of the problem and provides insight into how to eliminate them.

The operational working of the machine was considered for the FTA. FTA is not a cause and effect diagram. FTA can be used when the problem has already occurred in the current business process. As the case of the project was of current business process, FTA was used instead of FMEA. FMEA or failure mode and effect analysis is used for "what can happen," whereas FTA is used for "what has happened." FTA is a method to analyse a failure mode in order to identify possible assignable causes and find the failure mechanism [25]. FTA connects failure mode to assignable causes.

In this case study the fault tree was started from the definition of problem and then it was directed to primary causes and secondary causes. This procedure was followed till all possible causes were listed. FTA provided all areas to be improved in single view and helped in stepwise analysis. The critical parameters were segregated from experience of the persons using the machine and further analysis was carried out on these key input parameters. Figure 4 represents the fault tree drawn for the case study.

Factors that were considered the most influential key inputs are shown in Figure 5.

Once the key inputs were obtained from the FTA, there was a need to check the reliability of all the readings taken by the operators. This was done by performing measurement system analysis. Three inspectors measured two blocks separately once in a serial order and then in a random order. These readings were analysed using Minitab software to check the gage reproducibility and repeatability [6]. Figure 6 was the outcome of the measurement system analysis.

From the above results around $90 \%$ confidence level was obtained. Thus there was no error in measurement system and now all the readings can be called Data.

The third objective of this phase was to find out how they are related. The continuous key inputs, namely, slide pressure, lever pressure, ambient temperature, and oil temperature, were analysed using one of the multivariable regression analyses. Tests that can be used in this phase are regression, correlation, analysis of variance, hypothesis testing, $t$-tests, chi-squared tests, graphical analyses, GLM, logistic regression, and so forth. These tests come under Multi-Vari Studies. Before proceeding, to select the test, type of data was analysed.

Multi-Vari analysis is a graphical tool, which, through logical subgrouping, analyzes the effects of categorical $X$ 's on continuous $Y$ 's. The graphical results of Multi-Vari analysis can be quantified using nested analysis of variance.

Multi-Vari was chosen because of the following reasons:

(1) to determine with high statistical confidence the capability of the KPOVs of a process,

(2) to identify assignable causes of variability,

(3) to obtain initial components of variability (shift-toshift, run-to-run, and operator-to-operator),

(4) to get a first look at process stability over time,

(5) to provide direction and input for design of experiments (DOE) activities.

Selection of Test to Be Performed. The selection of test depends on the type of data whether it is continuous or discrete, single inputs or multiple inputs, single outputs or multiple outputs, and so forth. In this study, depth variation, that is, $Y$, and all the $X$ 's were continuous, so multiple regression analysis was performed as seen from Figure 7.

The general equation of approach was

$$
y=f\left(x_{1}, x_{2}, x_{3}, \ldots, x_{k}\right) .
$$

Depending on the key inputs obtained from the FTA, the data was sorted into continuous and discrete data. MultiVari regression analysis was performed for the continuous data. The key inputs varying continuously with time included slide pressure, lever pressure, ambient temperature, and the oil temperature. As the data was categorized as continuous, the data collection was done depending on time. Data was collected during all three shifts. The slide pressure, lever pressure, oil temperature, and ambient temperature were noted for every bore. Per shift 2 engine blocks were considered for this data collection. The data was collected at the start of each shift and at the end of each shift.

Before performing the regression analysis, null hypothesis $\left(\mathrm{H}_{0}\right)$ was set. Null hypothesis $\left(\mathrm{H}_{0}\right)$ is equal to the specified 


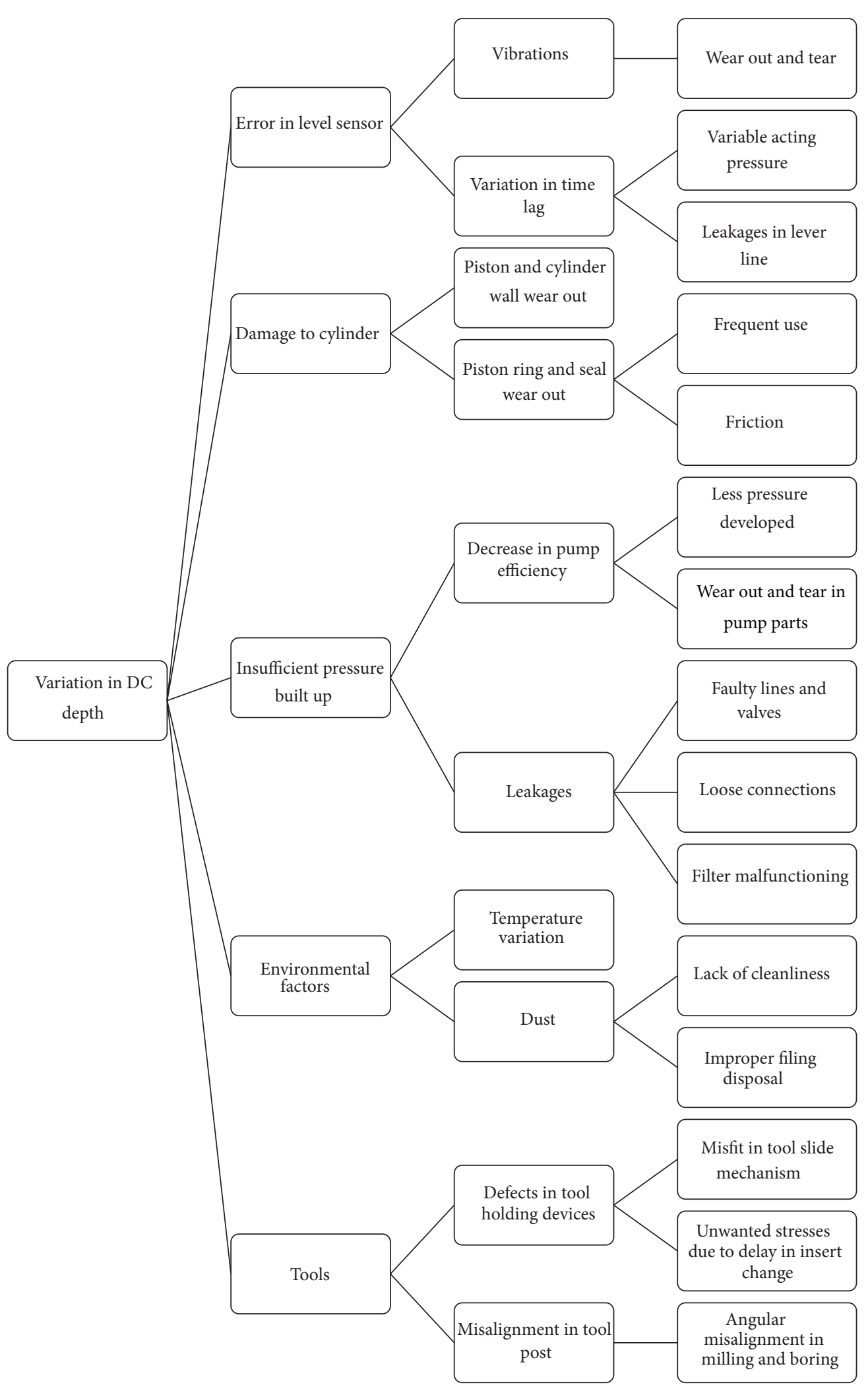

FIgURE 4: FTA. 


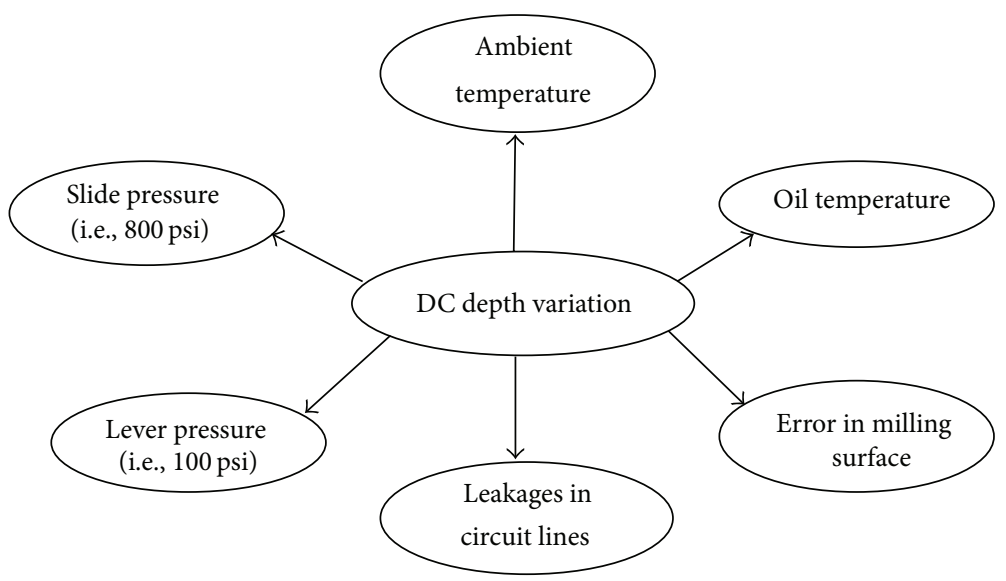

Figure 5: FTA key inputs.

value or parameter from another population. Alternative hypothesis $\left(\mathrm{H}_{\mathrm{a}}\right)$ is not equal to the specified value or parameter from another population. $P$ value is the value used to reject or fail to reject the null hypothesis. A is the probability that true null hypothesis is rejected:

$$
\begin{gathered}
\text { If } P \leq \alpha-\text { Reject } \mathrm{H}_{0}, \\
\text { If } P>\alpha-\text { Fail to reject } \mathrm{H}_{0} .
\end{gathered}
$$

The statistical analysis is done with the development of a theory, null hypothesis. The analysis will "fail to reject" or "reject" the theory.

Null Hypothesis $\left(\mathrm{H}_{0}\right)$ : data are independent (not related).

Alternative Hypothesis $\left(\mathrm{H}_{\mathrm{a}}\right)$ : data are dependent (related).

If the $P$ value is $\geq 0.05$, then accept the $\mathrm{H}_{0}$ (no statistical relationship).

If the $P$ value is $<0.05$, then reject $\mathrm{H}_{0}$ (a statistical relationship exists).

According to this theory it was assumed that the inputs ambient temperature, oil temperature, slide pressure, and lever pressure were not affecting the process; that is, the $X$ and $Y$ are not related. Thus it was called null hypothesis $\left(\mathrm{H}_{0}\right)$. Once the null hypothesis was set, the very first step was to find the correlations between each of the four inputs, that is, ambient temperature, oil temperature, slide pressure, and lever pressure. Figure 7 shows the correlation results provided by Minitab software. From Table 1 it can be easily seen that correlation exists only between ambient temperature and oil temperature. Thus, for regression, slide pressure and lever pressure can be neglected.

Once the correlation test was done, the next step was to perform multiple regression using the terms obtained from correlation test, that is, oil temperature and ambient temperature.

For the left bank the multiple regression failed. The results and residual plots obtained are shown in Figure 8 and Table 2.
TABLE 1: Correlation results from Minitab.

\begin{tabular}{lccc}
\hline \multicolumn{4}{r}{ Correlations: amb temp., oil temp., slide pr., lever pr. } \\
& Amb. temp. & Oil temp. & Slide pr. \\
\hline \multicolumn{4}{c}{ Correlation for left bank } \\
Oil temp. & 0.790 & $*$ & \\
Slide pr. & $*$ & $*$ & $*$ \\
Lever pr. & $*$ & $*$ & \\
\hline \multicolumn{4}{c}{ Correlation for right bank } \\
Oil temp. & 0.091 & $*$ & $*$ \\
Slide pr. & $*$ & & \\
Lever pr. & $*$ &
\end{tabular}

Cell Contents: Pearson correlation.

${ }^{*}$ All values in column are identical.

TABLE 2: Minitab results for regression LB.

\begin{tabular}{lcccc}
\hline \multicolumn{5}{c}{ Regression analysis: down versus amb temp., oil temp. } \\
\hline \multicolumn{5}{c}{ The regression equation is } \\
down $=0.712+0.000077$ amb. temp. +0.000126 oil temp. \\
21 cases used, 1 case contain missing values \\
\hline Predictor & Coef. & SE Coef. & $T$ & $P$ \\
\hline Constant & 0.712296 & 0.002422 & 294.07 & 0.000 \\
Amb. temp. & 0.00007696 & 0.00003924 & 1.96 & 0.066 \\
Oil temp. & 0.00012577 & 0.00009384 & 1.34 & 0.197 \\
\multicolumn{4}{c}{$S=0.000293334, R$-Sq $=60.0 \%, R$-Sq (adj) $=55.5 \%$} \\
\hline
\end{tabular}

It can be observed from Table 2 that the $P$ value is zero, that is, $\leq 0.05$. Thus, null hypothesis $\left(\mathrm{H}_{0}\right)$ is accepted. But the variance, that is, $R$-Sq, value is just $60 \%$. The $R$-Sq value must be at least $80 \%$ for multiple regressions to be successful.

Figure 9 and Table 3 show the residual plots and results for Right Bank of the engine block. It can be seen that the $R$-Sq value is very low for right bank, which is just $39 \%$. Thus these results are strictly rejected. The multiple regression analysis for left as well as right banks is not successful.

The null hypothesis $\left(\mathrm{H}_{0}\right)$ set that there is no relation between the $X$ 's and the $Y$ was true. Thus we fail to reject 
MSA study liner bore counter depth -KVBLOCK -INGERSOLL-AUG'10

Gage name: depth dial

Date of study: 24/09/10

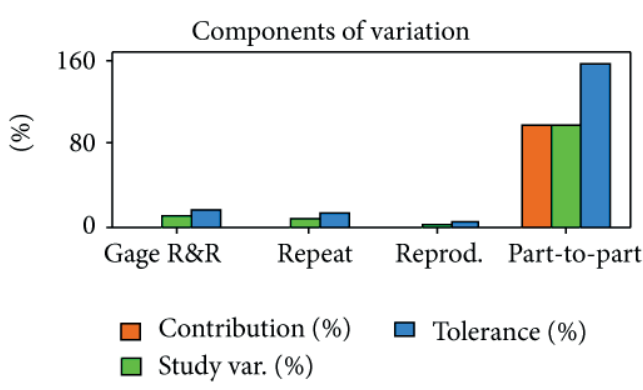

$R$ chart by operator

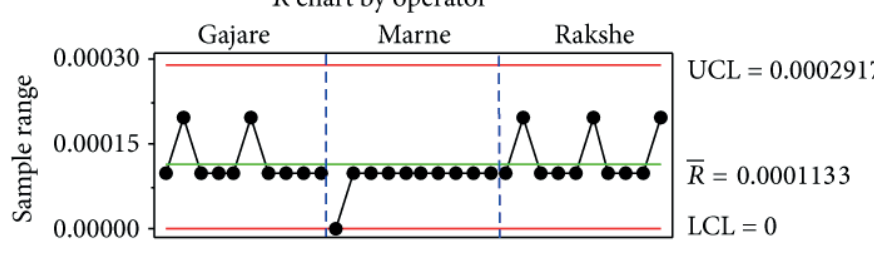

$X$ bar chart by operator

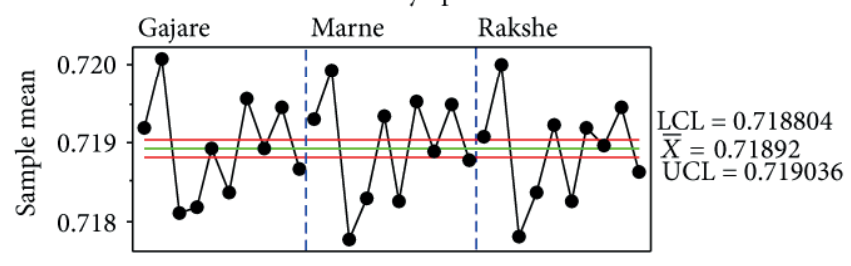

Reported by: Anil

Tolerance: 0.0001 "

Misc:
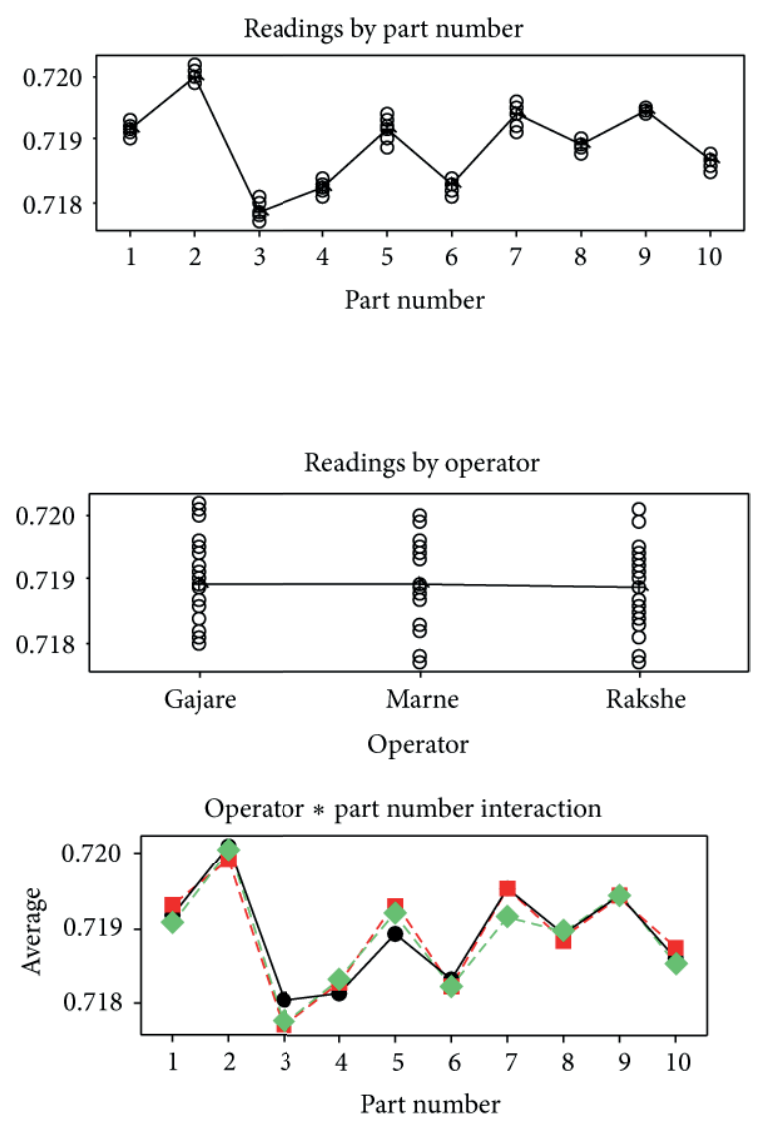

Operator

- Gajare

Figure 6: MSA plots.

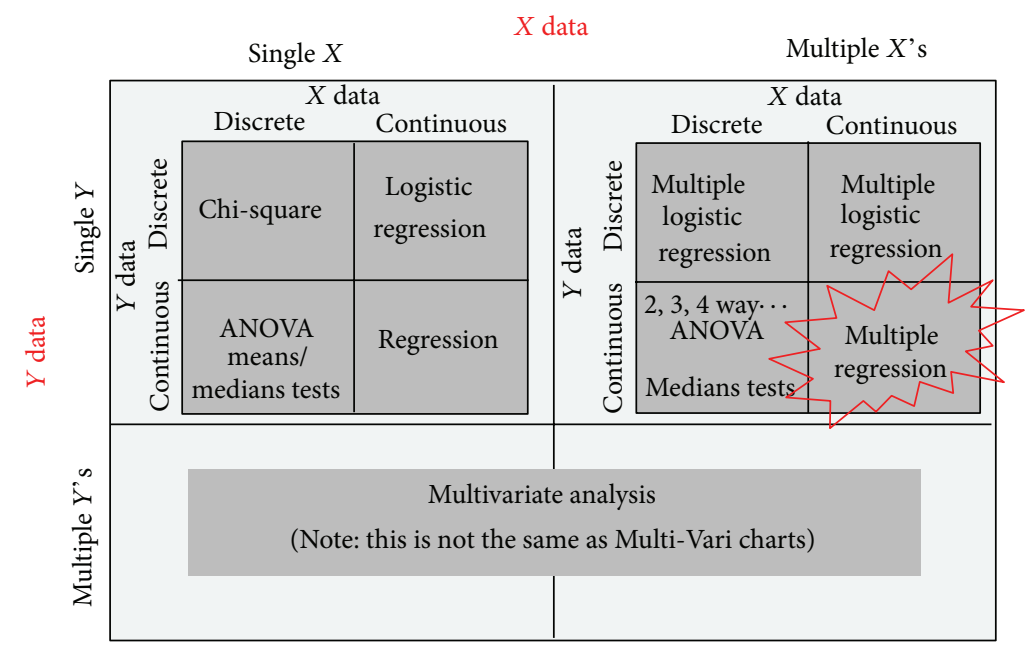

Figure 7: Selection of test for analysis [35]. 

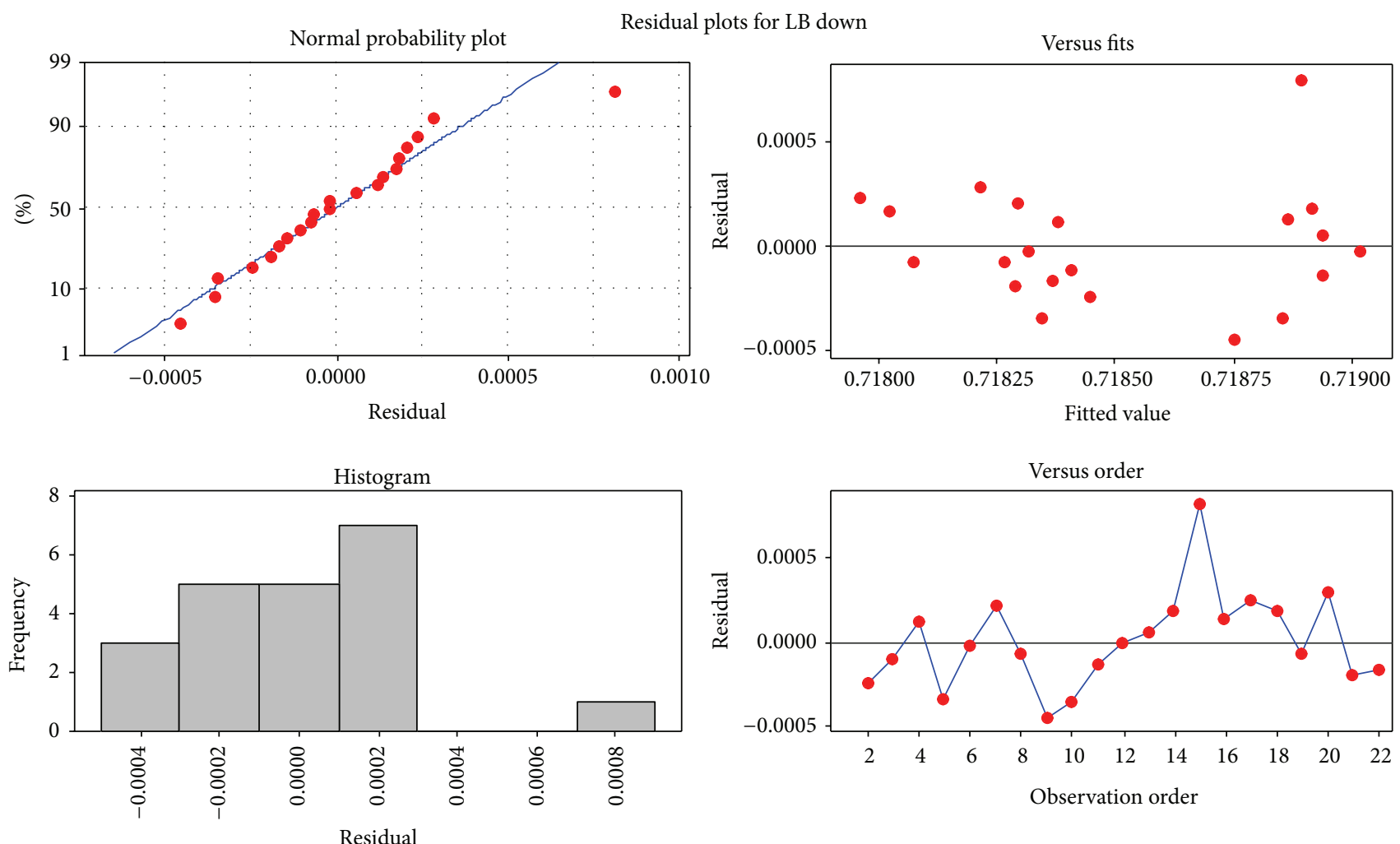

FIgUre 8: Residual plots of LB.
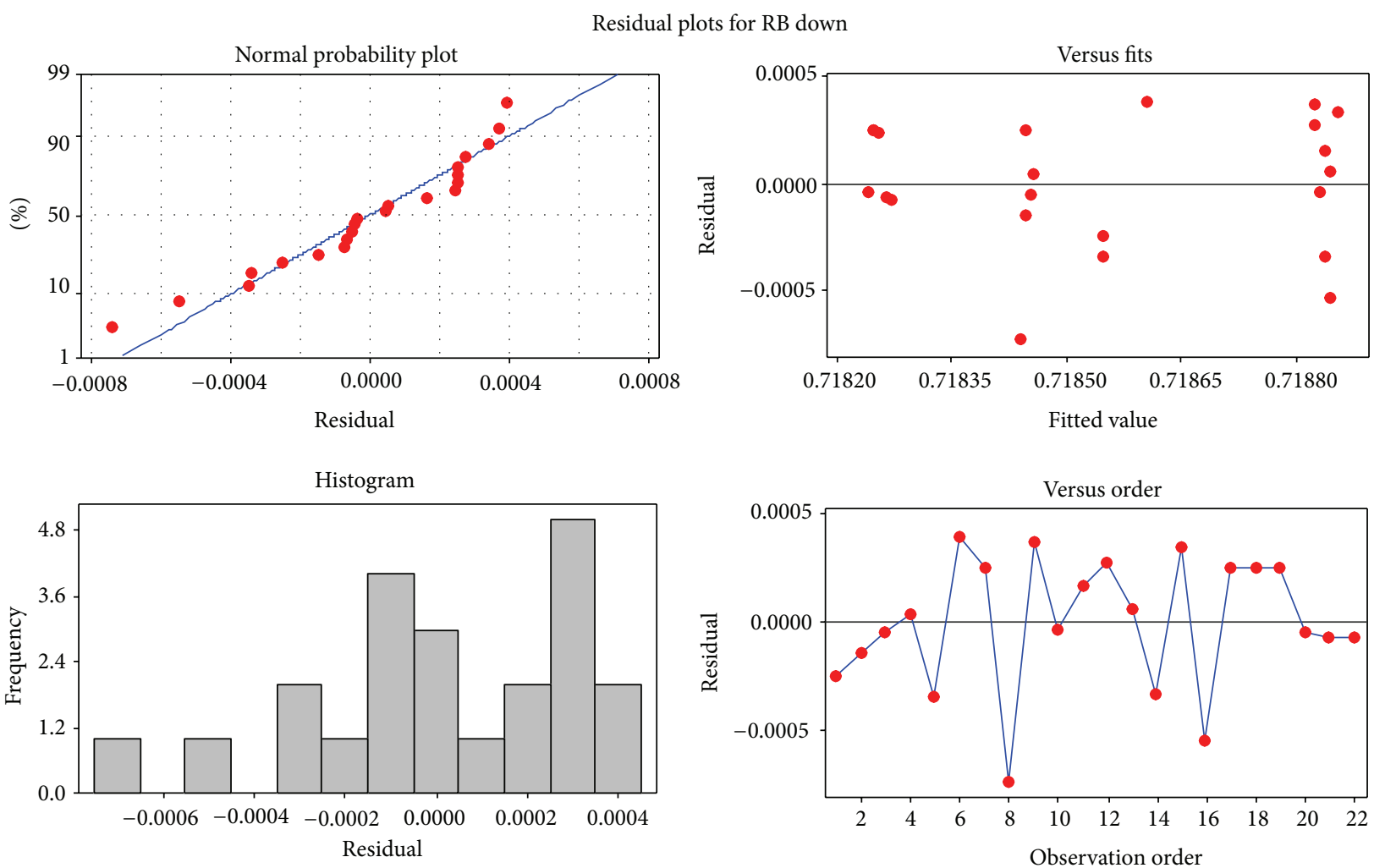

FIGURE 9: Residual plots for right bank. 
TABLE 3: Minitab results for multiple regression of RB.

\begin{tabular}{lcccc}
\hline \multicolumn{5}{c}{ Regression analysis: down versus amb. temp., oil temp. } \\
\hline \multicolumn{5}{c}{ The regression equation is } \\
down $=0.718+0.000097$ & amb. temp. -0.000060 oil temp. \\
\hline Predictor & Coef. & SE Coef. & $T$ & $P$ \\
\hline Constant & 0.718100 & 0.003310 & 216.97 & 0.000 \\
Amb. temp. & 0.00009655 & 0.00002780 & 3.47 & 0.003 \\
Oil temp. & -0.00005955 & 0.00009589 & -0.62 & 0.542 \\
\multicolumn{5}{c}{$S=0.000320196, R$-Sq $=39.0 \%, R$-Sq (adj) $=32.6 \%$} \\
\hline \multicolumn{5}{c}{}
\end{tabular}

the null hypothesis $\left(\mathrm{H}_{0}\right)$. It was concluded that the four key process input variables do not really dominate in contribution to key process output variable. Hence some other parameters were dominating the output. This could be easily seen from the regression equation as well as the residual plot. Two rifle shot inputs were obtained from the FTA, namely, leakages in the hydraulic circuit and errors in milling surface.

5.4. Step IV-Improvement. As the hydraulic circuit worked with high pressure of $800-1000$ psi, leakage was the factor responsible for pressure drop in the circuit. Hydraulic circuit was of very complex nature, involving many directional control valves and many pressure switches. There were many pressure switching actions causing stress on various joints. These leakages were creating problem to maintain pressure. Leakages were observed on both banks of the machine. As pressure maintaining was critical, all leakages were removed. These leakages were removed by cleaning all the pipes and valves in the circuit and changing pipes which were cut. After removing the leakages the rework percentage dropped but the change was not significant. Thus it was decided to check for milling surface error and remove if any.

Boring operation needs to be performed precisely as it can go wrong very easily. It requires precise alignment with drilled hole as well as surface on which hole is drilled. Alignment with drilled hole never creates a problem. Alignment with surface was another critical issue involved, especially when the surface was inclined. Surface alignment with boring tool was perfectly perpendicular when the machine was manufactured. But in course of time due to vibrations and other undesirable actions, misalignment was produced in the milling head, that is, milling surface, and boring tool, which created undesirable difference between up and down depths of step bore. On performing the analysis it was observed that the difference between up and down readings was $0.0040^{\prime \prime}$ which was almost $40 \%$ of total allowable tolerance. Thus a sleeve of $0.0040^{\prime \prime}$ was manufactured and inserted behind the milling head. The front view of sleeve is shown in Figure 10 where " $b$ " $=0.0040 "$ ".

This solved the problem significantly and the results were proven by plotting I-MR charts for rework.

After making the suggested improvements, the rework data was collected similarly as collected in Define phase. The I-MR chart was plotted and both charts were compared to study the results obtained before and after making improvements.

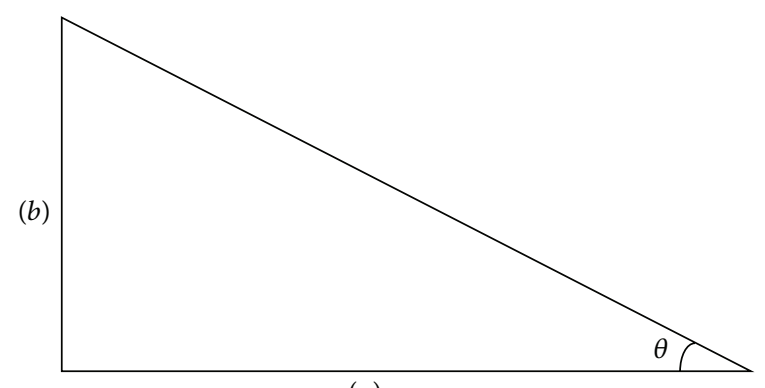

FIGURE 10: Milling head slide sleeve front view.

The I-MR chart of the revised rework for 3 months is shown below. It can be seen that the rework has been reduced to approximately $0 \%$ in March 2013. The value of mean rework for the months of April 2012-December 2012 was $16 \%$. After doing the improvements to the machine the rework reduced continuously from January 2013. In January the rework was $4.22 \%$. For the month of February 2013 the rework was further reduced to $2.33 \%$. The main objective was achieved in March 2013. The percentage rework dropped drastically to $0.33 \%$. Thus the target to make rework close to zero was successfully achieved.

At the beginning there was a lot of variation in the depths of bores of a single block. With reduction in rework, the other aim was to reduce this variation in the depth of the bores. This variation in depths was nonuniform. As discussed earlier the variation for a bore may go oversize and the very next bore would be undersize. On completion of the Improvement Phase, the box plot was plotted to compare the moving rages of the depths of the blocks which is shown in Figure 12. It could be observed that the moving range in March 2012 varied from $0.7170^{\prime \prime}$ to $0.7210^{\prime \prime}$ for a block. In November 2012 , this moving range was decreased. It varied from $0.7183^{\prime \prime}$ to $0.7205^{\prime \prime}$. Thus the improvement could be seen. In March 2013 this range was drastically decreased and the new range variation was between $0.7187^{\prime \prime}$ and $0.7195^{\prime \prime}$ thus making the variation uniform within less moving range.

5.5. Step V-Control. After completing the Improve phase, factors affecting the depth variation of the step bore were proposed. The actions proposed were implemented in the manufacturing process. The results of these improvements were monitored in Control phase. A control plan was prepared which is the major action of this phase. This control plan consisted of all the actions that were proposed for decreasing the rework of the blocks. It included training and certifying the operators, employees, maintenance plan preparation, regular inspection, and preparation of control charts. And thus from Figure 11, it can be observed that the goal set of reducing the rework to zero percent was achieved.

\section{Results}

The case study was carried out on a special purpose machine developed by Ingersoll. The machine was in continuous 
I-MR chart of \% no. of bores reworked by project phase
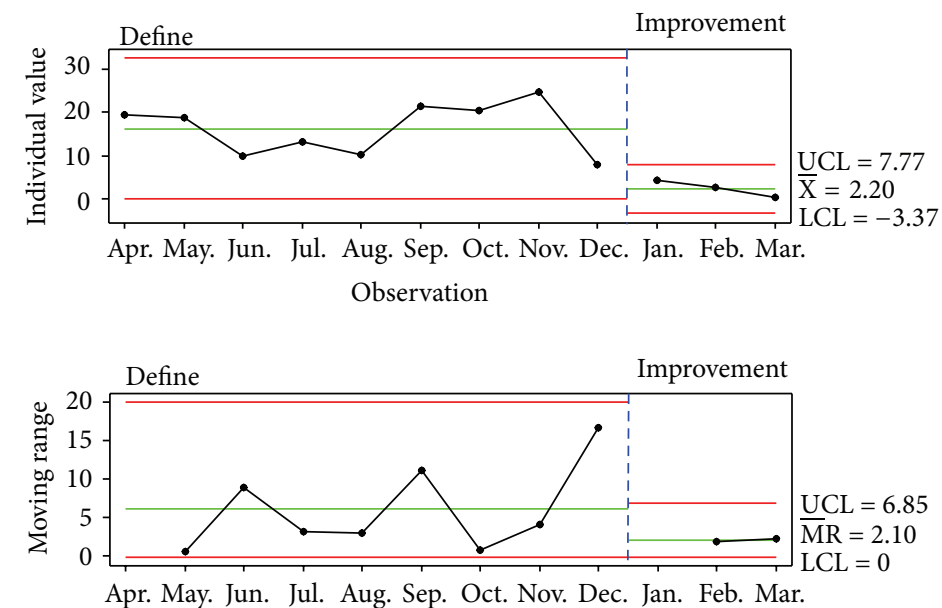

Observation

FIGURE 11: I-MR chart after improvement.

production for last 40 years. The hydraulic circuit components, seals, hoses were worn out resulting in the inefficient working of the machine. This was leading to high percentage rejection of the engine blocks. The study was carried out in phases and the principles of DMAIC were proved to be useful for reducing the rework rate and hence improving the productivity of the machine. As the machine was in operation and there were many factors contributing to deformation of the surface, it was difficult to carry out the experimentation for finding the reasons for the rework. Hence the FTA was selected for the purpose.

At the first stage the goals were set to reduce the rework from $16 \%$ to the minimum possible value as the cost of rework was very high and small deviation in work could reject the entire engine block. Later at Measurement phase, the actual measurement of deviation was carried out. It was found that the left bank of the engine was prone to deviation as compared to the right bank. Hence concentration was focused on this part of the engine block. The analysis of the deviation was an important issue. Probable reasons for the deviation were listed and categorized and the FTA was performed. After discussion with the experienced staff actually working on the machine, the principle factors contributing more to the deviation were identified for the study. The key inputs thus obtained from the FTA were needed to be checked for the reliability of all the readings taken by the operators. This was done by performing measurement system analysis. The results are shown in Figure 6. The multivariable regression analysis was performed to understand the relationship between the parameters. Figure 8 shows the residual plots for the left bank; from Table 2 it was observed that the $R-S q$ value is just $60 \%$ for the left bank. Figure 9 shows residual plots for right bank, and from Table 3 it was observed that the $R$-Sq value is just $39 \%$. For the multivariable regression test, to be successful, the $R-S q$ value must be at least $80 \%$. Thus it was found that the four key process input variables were not

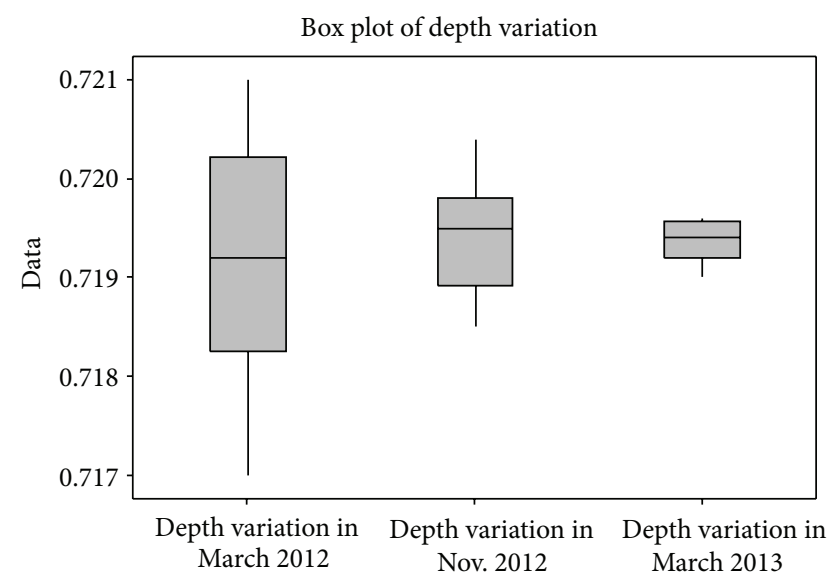

FIGURE 12: Box plot for depth variation.

dominating the key process output variable on both banks. Thus some other parameters were dominating the output. FTA provided the inputs, namely, leakages in the hydraulic circuit and errors in locating milling surface which were then studied for the performance.

The entire machine was operating on a complex hydraulic circuit with an oil pressure in the range of $800-1000$ psi. The leakages in the hydraulic circuit were traced and removed. The results of this step showed improvement in the process but were not significant. Another parameter was the milling head location error. It was removed by inserting a sleeve as shown in Figure 11. This time the efforts worked and the rework was reduced drastically close to $2.20 \%$ on average for 3 months. A control plan for all the contributing factors was prepared for reducing the rework. It included training and certifying the operators, employees, maintenance plan preparation, regular inspection, and preparation of control charts for further reduction in the rework. Figure 12 shows 
the improvement in the process after the DMAIC was successfully implemented for the machine.

\section{Conclusion}

Industries have to deal with a host of problems related to quality control. Substandard quality hampers the productivity of the plant which directly affects the company targets. Organizations have to suffer huge losses which are not easy to cope up with. Thus there is a need to improve the productivity simultaneously keeping in mind the quality of the product. Six Sigma can be effectively applied and the existing business processes can be improved and made error free. Six Sigma provides statistical proof to each and every action, thus helping making decisions more efficient. It can work even with less number of readings in the database. Thus Six Sigma is completely an industry oriented methodology of quality and productivity improvement.

In the presented case study the rework percentage was much higher, that is, $16 \%$. The firm had to sustain the rework cost and the man-hours required in the reworking decreased the productivity. Establishing the relationship between the input parameters and the output parameter is a challenge in a complex system like the one discussed above. The decision of using Six Sigma methodology proved to be facile. FTA was implemented to find all the key inputs that are affecting the output. The KPIVs were categorised as continuous and discrete depending on their property whether they vary with time or not and were analysed using multivariable regression analysis. The Multi-vari regression analysis proved that the selected continuous parameters were not dominating the output, failing to reject the null hypothesis $\left(\mathrm{H}_{0}\right)$; that is, these input variables did not affect the output. Hence, the rifle shot input parameters leakages in hydraulic circuit and milling surface errors were checked. Leakages were observed in the circuit for the left bank. These leakages were removed. The milling surface error was removed by inserting a sleeve as shown in Figure 10. After these errors were removed, the rework reduced to $2.20 \%$ per month thus achieving the set goal. The rework time of 369 hours per month was reduced to 42 man-hours per month. The cost of rework was reduced to USD 3500 per year. Thus there was significant improvement in the productivity and losses the firm incurred.

It is thus concluded that Six Sigma methodologies could be applied successfully in small firms. Practitioners could refer this case study and implement it in a similar kind of study. With the help of case study we try to prove that Six Sigma tools help to reduce the wastage and help improve quality of product. In this study we had considered limited parameters that affected the output. Depending upon the expert's experience, the study and improvements were done on milling surface errors and leakages. By performing experimentation on other parameters from the KPIVs, further improvements could be done. This would reduce the rework closer to zero in the future. DOE can be planned for the remaining KPIVs which can provide detailed effects on the output.

\section{Abbreviations}

DMAIC: Define, Measure, Analyse, Improve, and Control DMADV: Define, Measure, Analyse, Design, and Verify ROA: Return on asset

FTA: $\quad$ Fault tree analysis

FMEA: Failure mode and effect analysis

MSA: Measurement system analysis

DOE: Design of experiments

$\mathrm{H}_{0}$ : Null hypothesis

$\mathrm{H}_{\mathrm{a}}$ : $\quad$ Alternative hypothesis

$R$-Sq: $\quad R$-squared value

KPIV: $\quad$ Key process input variables

KPOV: Key process output variable.

\section{References}

[1] Andrew Spencer, Optimising Surface Textures for Combustion Engine Cylinder Liners, Luleå University of Technology, 2010.

[2] "What is Cylinder Liner?" http://www.wisegeek.com/what-isa-cylinder-liner.htm.

[3] J. Antony and R. Banuelas, "A strategy for survival," Manufacturing Engineer, vol. 80, no. 3, pp. 119-121, 2001.

[4] G. Büyüközkan and D. Öztürkcan, "An integrated analytic approach for six sigma project selection," Expert Systems with Applications, vol. 37, no. 8, pp. 5835-5847, 2010.

[5] A. Y. T. Szeto and A. H. C. Tsang, "Antecedent to successful implementation of six sigma," Journal of Six Sigma and Competitive Advantage, vol. 1, no. 3, pp. 307-322, 2005.

[6] H. C. Hung and M. H. Sung, "Applying six sigma to manufacturing processes in the food industry to reduce quality cost," Scientific Research and Essays, vol. 6, no. 3, pp. 580-591, 2011.

[7] A. Saghaei, H. Najafi, and R. Noorossana, "Enhanced rolled throughput yield: a new six sigma-based performance measure," International Journal of Production Economics, vol. 140, no. 1, pp. 368-373, 2012.

[8] F. W. Breyfogle, Implementing Six Sigma: Smarter Solutions Using Statistical Methods, John Wiley \& Sons, New York, NY, USA, 1999.

[9] X. Zu, L. D. Fredendall, and T. J. Douglas, "The evolving theory of quality management: the role of six sigma," Journal of Operations Management, vol. 26, no. 5, pp. 630-650, 2008.

[10] C. T. Su and C. J. Chou, "A systematic methodology for the creation of six sigma projects: a case study of semiconductor foundry," Expert Systems with Applications, vol. 34, no. 4, pp. 2693-2703, 2008.

[11] U. D. Kumar, D. Nowicki, J. E. Ramírez-Márquez, and D. Verma, "On the optimal selection of process alternatives in a six sigma implementation," International Journal of Production Economics, vol. 111, no. 2, pp. 456-467, 2008.

[12] A. A. Junankar and P. N. Shende, "Minimization of rework in belt industry using dmaic," International Journal of Applied Research in Mechanical Engineering, vol. 1, no. 1, 2011.

[13] Y. H. Kwak and F. T. Anbari, "Benefits, obstacles, and future of six sigma approach," Technovation, vol. 26, no. 5-6, pp. 708-715, 2006.

[14] M. Swink and B. W. Jacobs, "Six sigma adoption: operating performance Impacts and contextual drivers of success," Journal of Operations Management, vol. 30, no. 6, pp. 437-453, 2012.

[15] J. A. Blakeslee Jr., "Implementing the six sigma solution," Quality Progress, vol. 32, no. 7, pp. 77-85, 1999. 
[16] G. J. Hahn, W. J. Hill, R. W. Hoerl, and S. A. Zinkgraf, “The impact of six sigma improvement-a glimpse into the future of statistics," The American Statistician, vol. 53, no. 3, pp. 208-215, 1999.

[17] M. Harry and R. Schroeder, Six Sigma: The Breakthrough Management Strategy Revolutionising the World's Top Corporations, Doubleday, New York, NY, USA, 2000.

[18] M. J. Braunscheidel, J. W. Hamister, N. C. Suresh, and H. Star, "An institutional theory perspective on six sigma adoption," International Journal of Operations and Production Management, vol. 31, no. 4, pp. 423-451, 2011.

[19] X. Li, J. Zhan, F. Jiang, and S. Wang, "Cause analysis of bridge erecting machine tipping accident based on fault tree and corresponding countermeasures," Procedia Engineering, vol. 45, pp. 43-46, 2012.

[20] D. M. Shalev and J. Tiran, "Condition-based fault tree analysis (CBFTA): a new method for improved fault tree analysis (FTA), reliability and safety calculations," Reliability Engineering and System Safety, vol. 92, no. 9, pp. 1231-1241, 2007.

[21] E. V. Gijo, J. Scaria, and J. Antony, "Application of six sigma methodology to reduce defects of a grinding process," Quality and Reliability Engineering International, vol. 27, no. 8, pp. 12211234, 2011.

[22] M. Xia, X. Li, F. Jiang, and S. Wang, "Cause analysis and countermeasures of locomotive runway accident based on fault tree nalysis method," Procedia Engineering, vol. 45, pp. 38-42, 2012.

[23] Y. Wang, Q. Li, M. Chang, H. Chen, and G. Zang, "Research on fault diagnosis expert system based on the neural network and the fault tree technology," Procedia Engineering, vol. 31, pp. 1206-1210, 2012.

[24] R. McClusky, “The rise, fall and revival of six sigma," Measuring Business Excellence, vol. 4, no. 2, pp. 6-17, 2000.

[25] A. E. Summers, "Achieving six sigma through FTA," in Proceedings of the Process Plant Reliability Symposium, Houston, Tex, USA, October 1997.

[26] H. de Koning and J. de Mast, "A rational reconstruction of six-sigma's breakthrough cookbook," International Journal of Quality and Reliability Management, vol. 23, no. 7, pp. 766-787, 2006.

[27] J. de Mast and J. Lokkerbol, "An analysis of the six sigma DMAIC method from the perspective of problem solving," International Journal of Production Economics, vol. 139, no. 2, pp. 604-614, 2012.

[28] M. H. C. Li, A. A. Al-Refaie, and C. Y. Yang, "DMAIC approach to improve the capability of SMT solder printing process," IEEE Transactions on Electronics Packaging Manufacturing, vol. 31, no. 2, pp. 126-133, 2008.

[29] M. H. C. Li and A. Al-Refaie, "Improving wooden parts' quality by adopting DMAIC procedure," Quality and Reliability Engineering International, vol. 24, no. 3, pp. 351-360, 2008.

[30] D. Starbird, "Business excellence: Six Sigma as a management system," in Proceedings of the Annual Quality Congress, pp. 4755, Milwaukee, Wis, USA, May 2002.

[31] http://en.wikipedia.org/wiki/Six_Sigma.

[32] "What is Six Sigma," http://www.isixsigma.com/new-to-sixsigma/getting-started/what-six-sigma/.

[33] G. W. Frings and L. Grant, "Who moved my sigma ...effective implementation of the six sigma methodology to hospitals," Quality and Reliability Engineering International, vol. 21, no. 3, pp. 311-328, 2005.
[34] R. McAdam and A. Evans, "Challenges to six sigma in a high technology mass-manufacturing environments," Total Quality Management and Business Excellence, vol. 15, no. 5-6, pp. 699706, 2004.

[35] http://www.six-sigma-material.com/Hypothesis-Testing.html. 

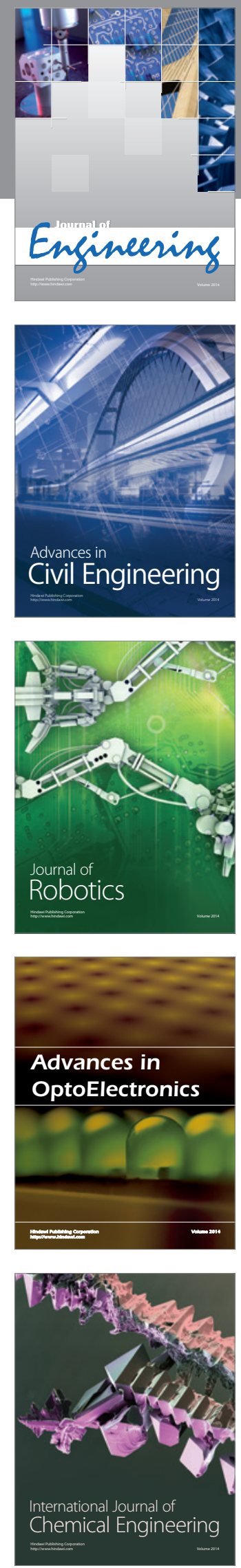

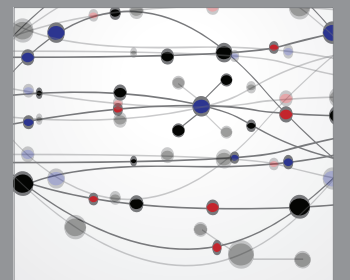

The Scientific World Journal
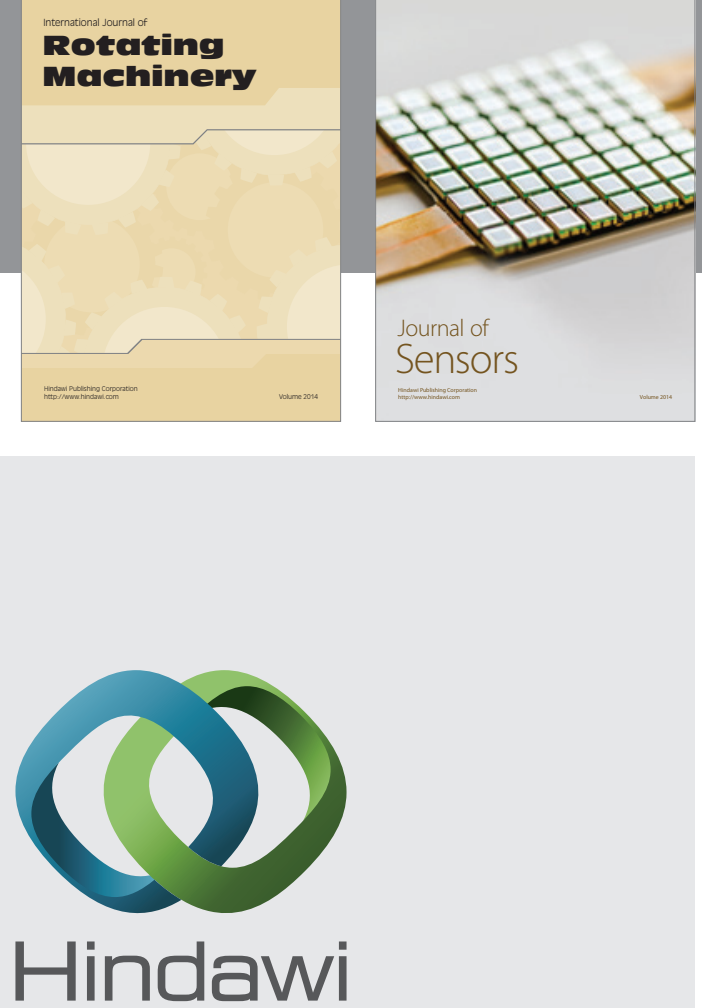

Submit your manuscripts at http://www.hindawi.com
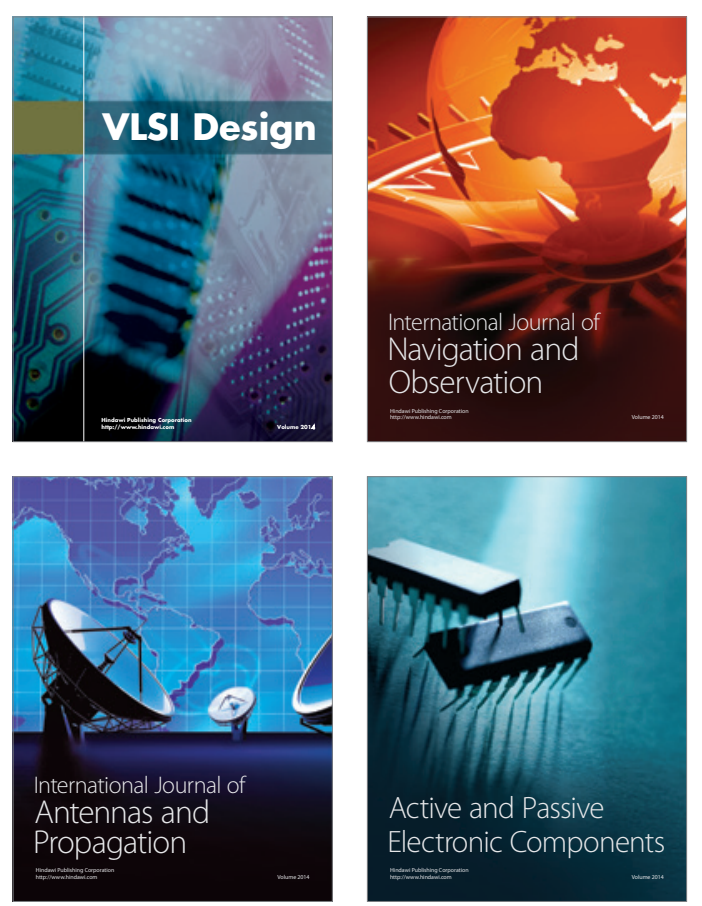
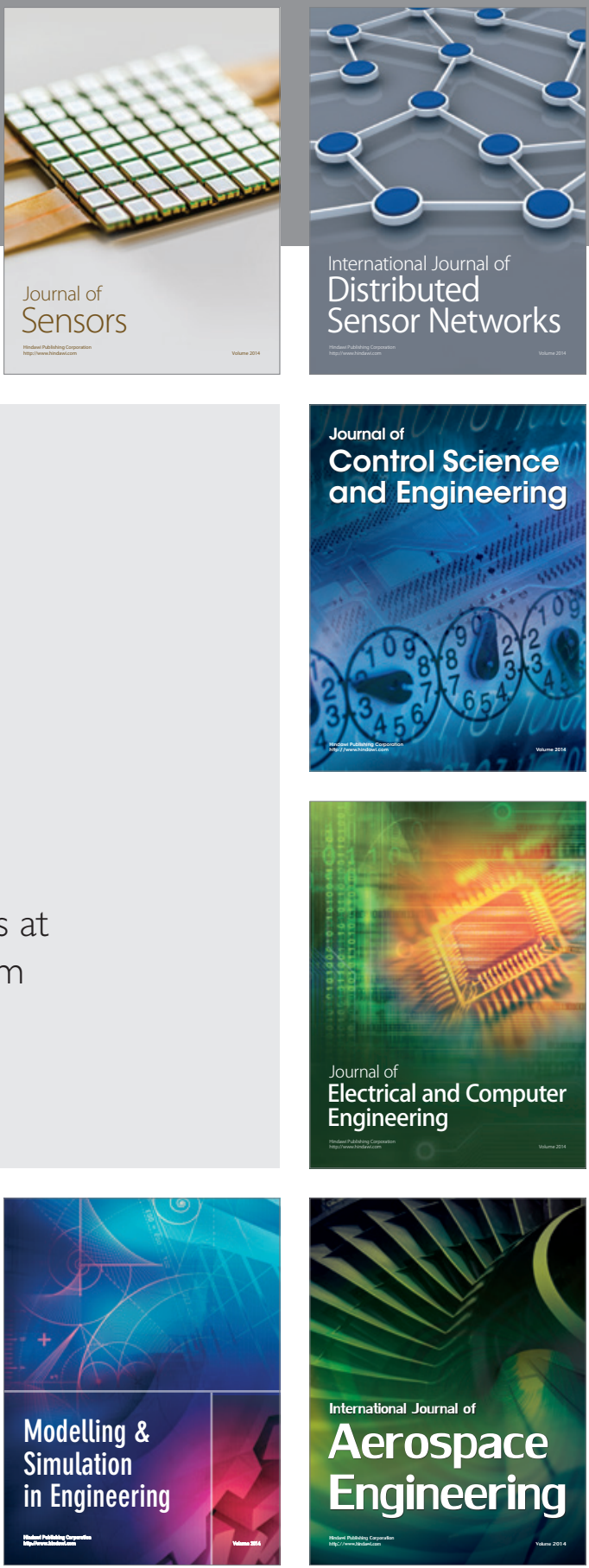

Journal of

Control Science

and Engineering
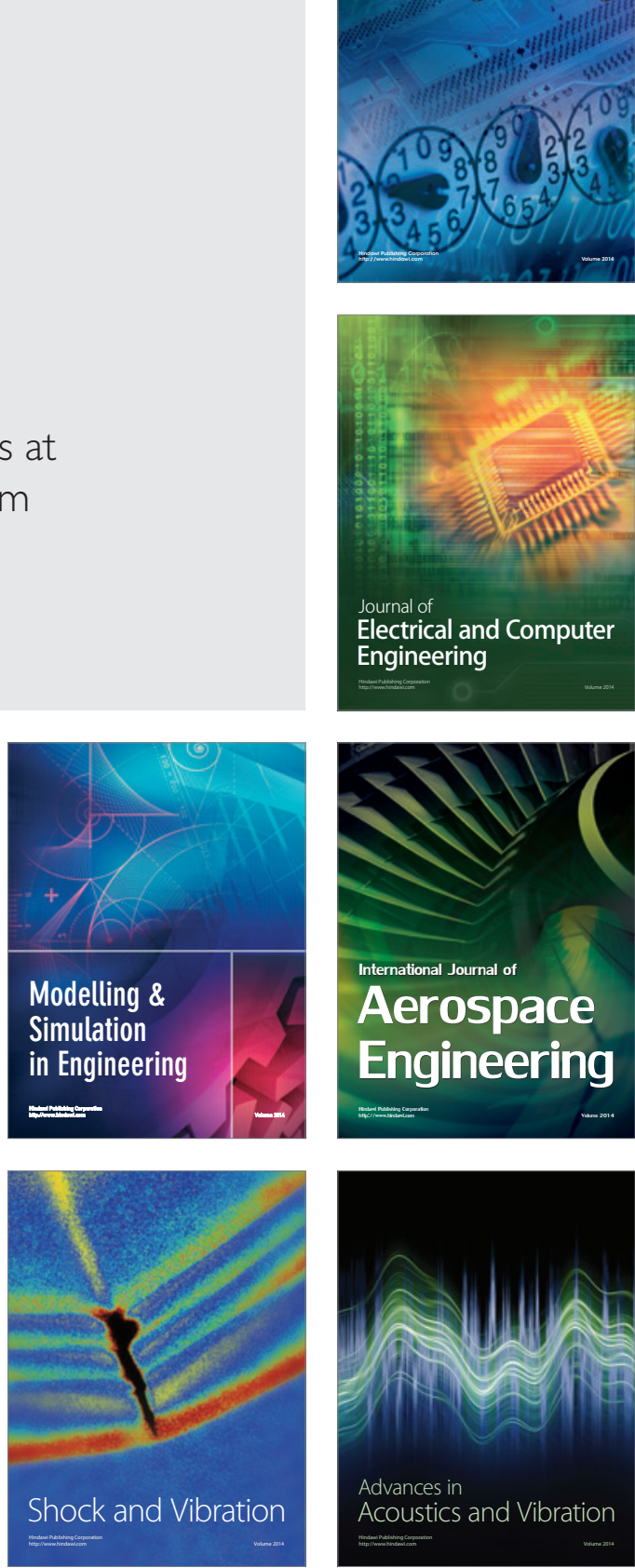